\title{
CARDS vs ARDS - implications for respiratory support
}

\section{KD Naidoo}

Division of Critical Care, University of the Witwatersrand, South Africa

Corresponding author, email: kuban.naidoo@wits.ac.za

\section{Summary}

Based on a handful of early reports and anecdotal experience, experts hypothesised that severe COVID-19 pneumonia was clinically different from the more classical presentation of the acute respiratory distress syndrome (ARDS), despite fulfilling the Berlin definition. The most striking difference noted was the dissociation of the severity of hypoxaemia and the compliance of the respiratory system $(\mathrm{Crs})$. It was proposed that patients were presenting along a time-related spectrum with two distinct phenotypes at either end. Initially, type 'L" is characterised by low elastance (high Crs), low lung weight, low right-to-left shunt, and low lung recruitment potential. With time, patients would eventually become type " $\mathrm{H}$ " with high elastance (low $\mathrm{Crs}$ ), high lung weight (oedema), high right-to-left shunt with greater potential for lung recruitment and thus resemble classical ARDS. Subsequently, numerous studies have examined the mechanics and gas exchange of COVID-19 patients and have found no consistent relationships between hypoxaemia, recruitability and compliance. There was no convincing evidence found of a timerelated spectrum of disease. In conclusion, despite significant variability, COVID-19 produces a clinical picture largely consistent with classical ARDS. Furthermore, the outcomes using traditional lung protective strategies have been acceptable and do not warrant change at this stage.

Keywords: acute respiratory distress syndrome, ARDS, COVID-19-associated ARDS, CARDS

\section{Background}

As the novel SARS-CoV-2 coronavirus spread around the world during the first half of 2020, clinicians who were treating the most severely affected patients in ICU began to suggest a difference between patients with COVID-19 pneumonia complicated by acute hypoxaemic respiratory failure and the more classical presentation of the acute respiratory distress syndrome (ARDS). ${ }^{1-3}$

Given the acute nature of severe COVID-19, the presence of pulmonary infiltrates and the severity of hypoxaemia which characterises the disease, most COVID-19 pneumonia patients admitted to ICUs do in fact meet the diagnostic criteria for ARDS as defined by the Berlin definition..$^{1,4}$ Despite this, the apparent dissociation between the severity of hypoxaemia and the relative conservation of respiratory system mechanics in some patients led to some experts postulating that COVID-19-associated ARDS (CARDS) may present with different phenotypes and may thus require different treatment approaches to those traditionally applied to the management of ARDS. ${ }^{1-3}$

Experts from Italy proposed that the interaction between three factors: the severity of the infection modified by host factors, the ventilatory responsiveness of the patient to hypoxaemia and the time interval from onset of the disease to presentation to hospital creates a time-related disease spectrum. ${ }^{1}$ At either end of this spectrum exists two distinct phenotypes: the so-called " $\mathrm{L}$ " and " $\mathrm{H}$ " types. Type " $\mathrm{H}$ ", characterised by high elastance (low respiratory system compliance [Crs]), high lung weight (oedema), high right-to-left shunt and high lung recruitment potential closely resembles classical ARDS while type "L" is characterised by low elastance (high $\mathrm{Crs}$ ), low lung weight, low right-to-left shunt and low lung recruitment potential. ${ }^{1,3}$ These distinct phenotypes would be easily distinguishable by CT scan, although Crs and response to positive end-expiratory pressure (PEEP) may serve as imperfect surrogates. ${ }^{1}$

The phenotypic time-related disease spectrum had several implications for the clinical management of these patients. Firstly, if type "L" precedes type " $\mathrm{H}$ ", then early application of appropriate interventions would potentially interrupt this progression. One of the proposed pathogenetic mechanisms leading to the progression of disease was patient self-inflicted lung injury (P-SILI), particularly if non-invasive respiratory support was applied to patients with vigorous respiratory efforts. ${ }^{1,3}$ This led to clinicians foregoing trials of non-invasive respiratory support in favour of early intubation and mechanical ventilation, usually with adjunctive use of neuromuscular blockade. ${ }^{5,6}$

Secondly, the relative preservation of Crs prompted considerations of reduced need of a traditional low tidal volume ventilatory strategy. The use of higher tidal volumes would have the benefit of enhanced removal of $\mathrm{CO}_{2}$ possibly attenuating dyspnoea (if spontaneously breathing) and limiting reabsorption atelectasis. ${ }^{2,3}$

Thirdly, the low right-to-left shunt and lack of recruitment potential among type " $\mathrm{L}$ " patients simultaneously limits the therapeutic value, while increasing the potential of adverse haemodynamic effects of higher levels of PEEP. ${ }^{1-3}$ This is particularly noteworthy given that the NIH-NHLBI ARDS Network 
guidance for application of PEEP is dictated by the fraction of inspired oxygen required by patients, which has been very high in COVID-19 pneumonia patients. ${ }^{7,8}$

Fourthly, like PEEP, the utility of the prone position in type " $\mathrm{L}$ " patients would be limited, and any benefit would be derived from improved distribution of perfusion rather than from dorsal recruitment of atelectatic alveoli. ${ }^{2}$ Lastly, the weaning process in these patients would need to be more cautious with limited use of spontaneous breathing trials aimed at avoiding abrupt increases in spontaneous efforts. ${ }^{3}$

The phenotype hypothesis appeared to be corroborated by an early French report of post-mortem lung biopsies from six COVID-19 pneumonia patients. One patient who died within the first week of illness had evidence of lymphocytic viral pneumonia. The remaining five, who died later in the disease course, had a histologic pattern of acute fibrinous and organising pneumonia characterised by extensive intra-alveolar fibrin deposition in addition to prominent vascular injury. This contrasts with the hyaline membranes which characterise diffuse alveolar disease, the hallmark of ARDS. The findings appeared to provide evidence of the " $L$ " type as well confirmation of a disease process distinct from ARDS. With respect to management implications, the fibrin exudates raised the possibility of a beneficial role of corticosteroids (which are not recommended for the general management of ARDS) while the obliterative pattern of lung injury cautioned against the use of high levels of PEEP. ${ }^{9}$

\section{Controversy and concerns}

The hypothesis that CARDS was distinct enough from ARDS to warrant deviation from accepted management approaches was soon met with opposition. ${ }^{10}$ Detractors expressed concerns about the paucity of experimental data confirming the presence and impact of P-SILI in humans, particularly as P-SILI was proposed as the primary reason for advocating the prioritisation of earlier intubation and initiation of mechanical ventilation in order to prevent the development of a P-SILI vortex..$^{3,10}$ This is highlighted against the backdrop of the worldwide surge in COVID-19 cases which demanded the availability of mechanical ventilators on an unprecedented scale. It is also worth remembering that this debate coincided with the phase of the COVID-19 pandemic wherein many practitioners and institutions were actively looking to avoid non-invasive forms of respiratory support such as high-flow nasal cannula (HFNC) and non-invasive ventilation (NIV) due to concerns of nosocomial spread of COVID-19 from aerosolisation of respiratory secretions. ${ }^{6,11}$

It was pertinently pointed out that invasive mechanical ventilation is itself associated with considerable risk of harm, particularly in the hands of unfamiliar providers as was the case with the pandemic. Furthermore, the recommendation to adopt a more cautious approach to weaning off mechanical ventilation would inevitably result in patients staying on ventilators for longer than perhaps warranted, further exposing them to the risks associated with invasive mechanical ventilation. ${ }^{10}$

\section{CARDS: Respiratory system mechanics and gas exchange}

In response to the reports of unusually preserved respiratory mechanics $\left(\mathrm{Crs}>50 \mathrm{ml} / \mathrm{cmH}_{2} \mathrm{O}\right.$ ) despite severe hypoxaemia, ${ }^{12}$ numerous investigators set out to describe the respiratory system mechanics and adequacy of gas exchange in patients with CARDS and compare their findings to historical data from patients with non-COVID-19 ARDS.11,13-17 The response of the patients to established ARDS management strategies was also examined, particularly the impact of higher levels of PEEP. $71,147-21$ The recently described recruitment-to-inflation $(\mathrm{R} / \mathrm{l})^{7}$ and ventilatory ratios $(\mathrm{VR})^{4}$ were utilised to quantify the potential for lung recruitment and the adequacy of ventilation respectively. The $\mathrm{R} / \mathrm{I}$ ratio, a bedside respiratory mechanics-based index, ranges from 0 to 2.0 with higher values suggesting greater potential for lung recruitment.? The VR, another bedside index, correlates with pulmonary dead space. Normally ventilating lungs would have a VR approximating 1 , with higher values indicative of impaired efficiency of ventilation. ${ }^{22}$ The results of selected studies are presented, in chronological order of publication, in Table I.

Overall, the studies revealed that patients with CARDS (with predominantly moderate or severe hypoxaemia) had highly heterogeneous respiratory system mechanics, consistent with previous reports of "typical" ARDS patients. The

Table I: Selected ventilatory characteristics of patients with CARDS

\begin{tabular}{|c|c|c|c|c|c|c|c|c|c|c|c|}
\hline & $\operatorname{Pan}^{7}$ & $\operatorname{Liu}^{4}$ & Mauri $^{18}$ & Ziehr"11 & Beloncle $^{19}$ & Schenck ${ }^{13}$ & Haudebourg ${ }^{21}$ & Diehl ${ }^{14}$ & Ferrando $^{15}$ & Grasselli' ${ }^{16}$ & Grieco $^{17}$ \\
\hline$n$ & 12 & 8 & 10 & 66 & 25 & 267 & 30 & 22 & 742 & 301 & 30 \\
\hline $\mathrm{PaO}_{2} / \mathrm{FiO}_{2}$ & 128 & 230 & 99 & 182 & 135 & 103 & 119 & 198 & 120 & 124 & 119 \\
\hline $\operatorname{Crs}\left(\mathrm{ml} / \mathrm{cmH}_{2} \mathrm{O}\right)$ & 20 & 34 & 47 & 35 & 45 & 28 & 44 & 40 & 35 & 41 & 41 \\
\hline Plat $\mathbf{P}\left(\mathrm{cmH}_{2} \mathrm{O}\right)$ & 30 & 24 & 16 & 21 & 23 & 25 & 21 & 27 & 25 & 24 & 15 \\
\hline PEEP $\left(\mathrm{cmH}_{2} \mathrm{O}\right)$ & 8 & 10 & 5 & 10 & 12 & 10 & 11 & 16 & 12 & 13 & 5 \\
\hline $\mathbf{V t}(\mathrm{ml} / \mathrm{kg})$ & 6 & 7.5 & 7.4 & - & 6 & 7 & 6 & 6 & 6.9 & 7 & 6.4 \\
\hline RI & 0.3 & - & 0.79 & - & 0.55 & - & 0.4 & - & - & - & 0.73 \\
\hline $\mathrm{PaCO}_{2}(\mathrm{mmHg})$ & 66 & 41.8 & 50.6 & - & 41 & 44 & - & 55 & 45 & 46 & 43 \\
\hline VR & - & 1.6 & 2.1 & 1.25 & - & 1.79 & - & 2.9 & 2 & 1.76 & 2.1 \\
\hline Prone usage (\%) & 59 & 0 & 0 & 47 & 0 & 40 & - & - & 76 & - & 70 \\
\hline NMB usage (\%) & - & - & 70 & 38.7 & 100 & 60 & - & - & 72 & - & - \\
\hline
\end{tabular}




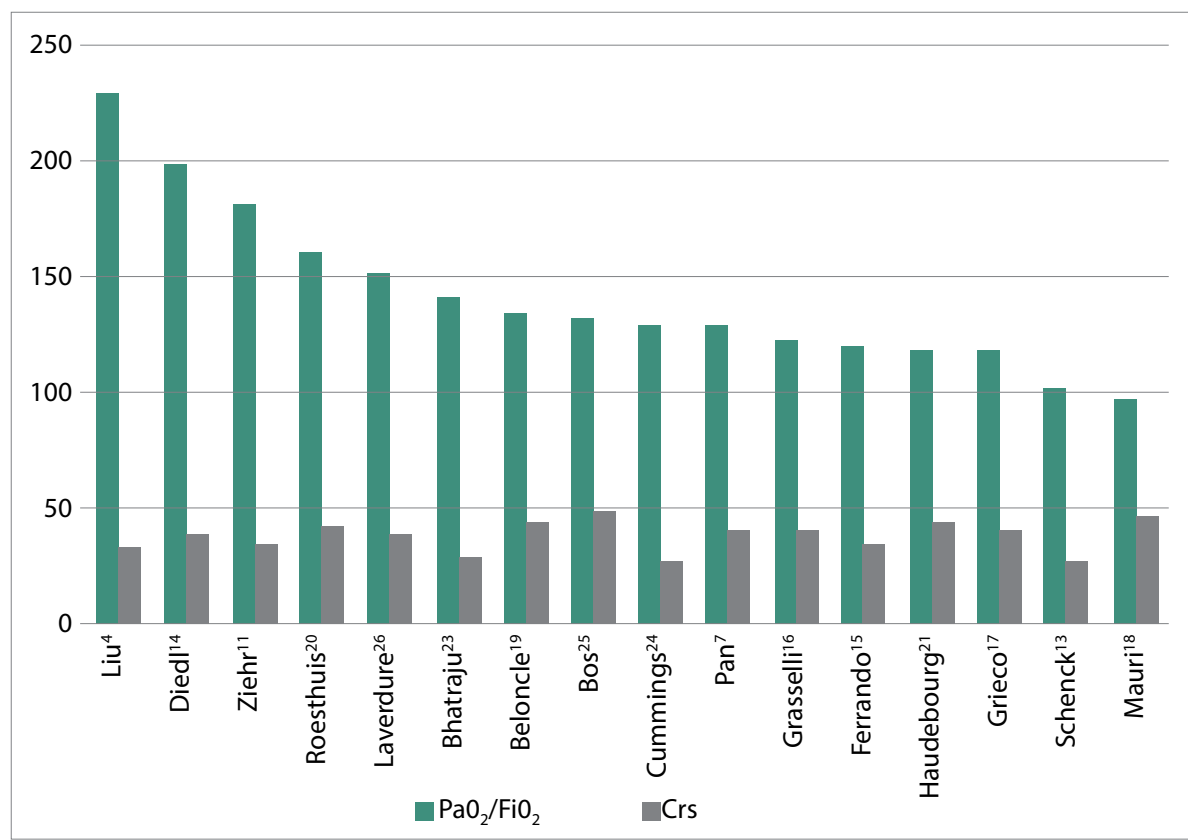

Figure 1: The relationships between $\mathrm{PaO}_{2}: \mathrm{FiO}_{2}$ and $\mathrm{Crs}$

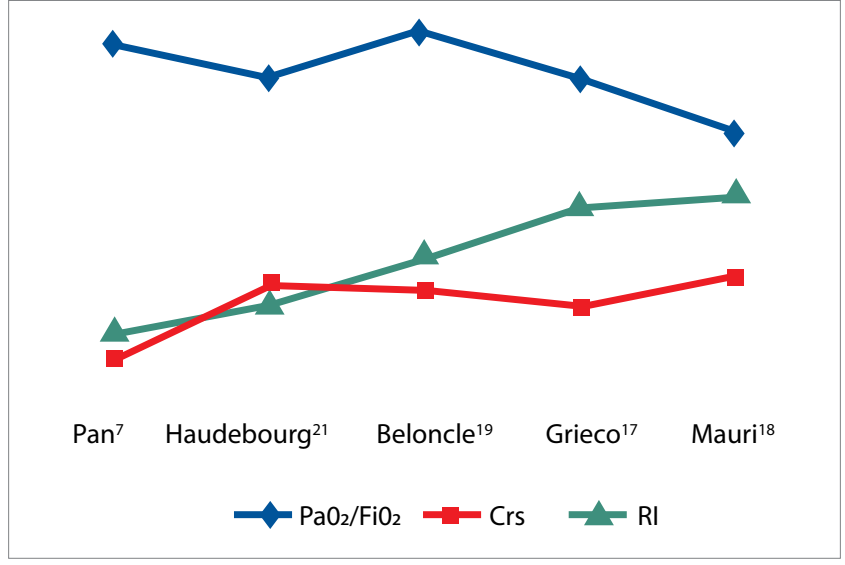

Figure 2: The relationships between $\mathrm{PaO}_{2}: \mathrm{FiO}_{2}, \mathrm{Crs}$ and $\mathrm{R} / \mathrm{I}$

reported median Crs values ranged widely $\left(20-47 \mathrm{ml} / \mathrm{cmH}_{2} 0\right)$, as did the corresponding median $\mathrm{PaO}_{2}: \mathrm{FiO}_{2}$ ratios $(99-230$ $\mathrm{mmHg}$ ), $4,7,11,13-21,23-26$ There appeared to be no predictable relationship between $\mathrm{Crs}$ and $\mathrm{PaO}_{2}: \mathrm{FiO}_{2}$ (Figure 1), confirmed by the lack of correlation in the two largest studies. ${ }^{15,16}$ This suggested highly variable contributions from loss of aeration (shunt) to the resultant hypoxaemia, in contrast to other ARDS cases.

Further, the Crs failed to correlate with either lung weight ${ }^{16,25}$ or potential recruitability. ${ }^{21}$ The relationships between Crs, $\mathrm{PaO}_{2}: \mathrm{FiO}_{2}$ and $\mathrm{R} / \mathrm{l}$ were reported in five studies (Figure 2). High recruitment potential $(\mathrm{R} / \mathrm{I}>0.5)$ despite relatively high $\mathrm{Crs}$ $\left(>40 \mathrm{ml} / \mathrm{cmH}_{2} \mathrm{O}\right.$ ) was noted in three ${ }^{17-19}$, together with wide interindividual variability. ${ }^{18}$ The remaining two studies noted low recruitability despite widely contrasting respective $\mathrm{Crs}$ values of 20 and $44 \mathrm{ml} / \mathrm{cmH} 20 .{ }^{7,21}$ What was much more consistent among the CARDs patients was evidence of impaired ventilation with $88 \%$ of studies reporting VRs greater than 1.5 revealing a notable contribution from inadequate ventilation to hypoxaemia., , $13-18^{-18}$ Somewhat modest increases in $\mathrm{PaO}_{2}$ (17\% and $28 \%$ ) resulted from the application of increased levels of PEEP. 18,19 However, the concomitant increase in VR hinted at hyperinflation, with the improved oxygenation possibly resulting from redistribution of perfusion rather than effective recruitment. ${ }^{18}$

Neither $\mathrm{Crs}^{11,21,26}$ nor R//18,21 correlated with days of ventilation. This can be either interpreted as a lack of evidence of time-related deterioration with CARDS or evidence of the efficacy of neuromuscular blockade to prevent P-SILI. Lastly, sub-groups of CARDS were identified in two studies. One separated patients on the basis of $\mathrm{Crs}$ (below or above $\left.40 \mathrm{ml} / \mathrm{cmH}_{2} 0\right)^{26}$ and the other on recruitability potential (using an $\mathrm{R} / \mathrm{l}$ cutoff of 0.5). ${ }^{20}$ However, neither groups of investigators were able to successfully find associations completely consistent with the " $\mathrm{L}$ " and " $\mathrm{H}$ " subtypes due to the mixed characteristics displayed by the patients. In summary, there was no evidence of distinct subphenotypes or a time-related spectrum among CARDS patients.

\section{Happy hypoxaemics}

Meanwhile, at the coal face, clinicians were being faced with everincreasing numbers of patients with severe hypoxaemia, despite high levels of supplemental oxygen. This clinical scenario would have usually prompted rapid progression to invasive mechanical ventilation. However, despite the recommendations discussed above, the reality was that early reports of the outcomes of mechanical ventilation were astonishingly poor, with mortality rates in excess of $80 \%$ and the demand for mechanical ventilators was rapidly overwhelming availability. ${ }^{27}$ Secondly, reports began to emerge of an uncommonly seen patient phenotype, coined "happy hypoxaemics" by the press. ${ }^{28}$ These were a group of patients with severe levels of hypoxaemia in the absence of evidence of either dyspnoea or end-organ dysfunction. The result was that clinicians started to employ respiratory support such as HFNC and NIV in ever-increasing numbers often in conjunction with "awake" prone positioning..$^{29,30}$ This was despite the fact that patients had $\mathrm{PaO}_{2}: \mathrm{FiO}_{2}$ ratios much lower than those generally thought to be reasonable for attempting those therapies. ${ }^{31,32}$ Additionally, there remained pressing concerns around these technologies and environmental contamination with the SARSCoV-2 virus placing the healthcare workers at significant risk. ${ }^{6,11}$

\section{Pathophysiology of 'happy' hypoxaemia}

Hypoxaemia with minimal evidence of respiratory distress, is not a unique feature of COVID-19, yet the sheer volume of cases demand consideration of the proposed underlying pathophysiology. The adequacy of gas exchange is determined by the relationship of ventilation to perfusion (V/Q matching). During the early phases of COVID-19, several mechanisms 


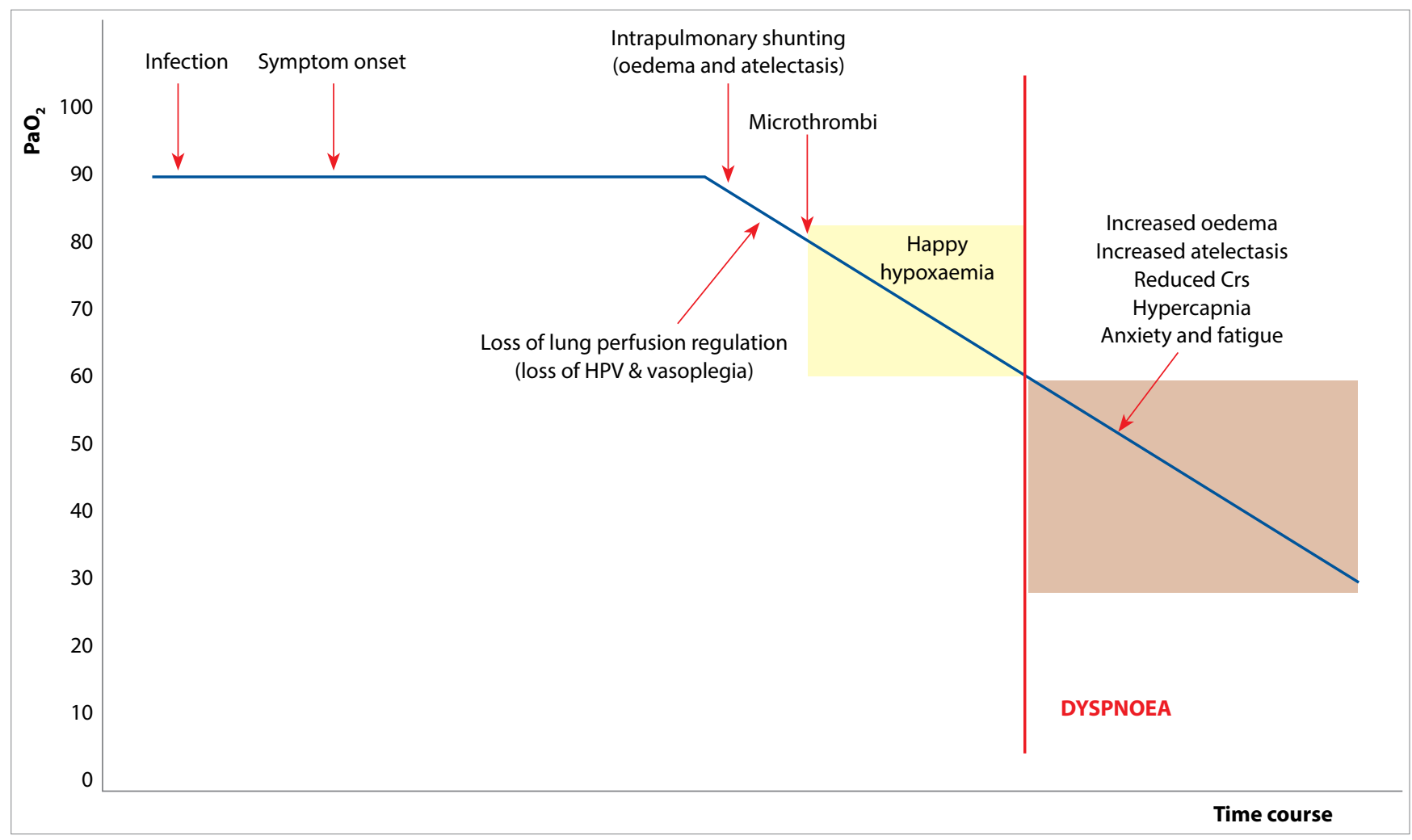

Figure 3: Mechanisms of hypoxaemia in COVID-1933

contribute to the development of hypoxaemia in the absence of marked increases in the effort of breathing (Figure 3). ${ }^{33}$

The viral parenchymal infection results in modest localised subpleural interstitial oedema (ground glass appearance) at the interface of structures with different elastic properties, where stress and strain are concentrated. ${ }^{1}$ Together with surfactant loss, the pressure exerted results in atelectasis, diminishing the amount of aerated (ventilated) tissue creating a V/Q mismatch. ${ }^{33}$

Angiotensin-converting enzyme 2 (ACE2) receptors are the principal receptors to which the SARS-CoV-2 virus binds to facilitate entry into host cells. ${ }^{33}$ These receptors are strongly expressed on endothelial cells and an emerging hallmark of COVID-19 is extensive endothelialitis with accompanying microthrombi. ${ }^{34}$ The extensive vascular network within the lungs predisposes to considerable pulmonary involvement which results in loss of lung perfusion regulation, consequently inactivating the pulmonary hypoxic vasoconstrictive response to a loss of aerated tissue, worsening the V/Q mismatch. ${ }^{14}$ The vasoplegia may actually increase the perfusion of gasless tissue further unbalancing the V/Q relationship. ${ }^{12}$

The widespread development of microthrombi (suggested by the common finding of impressively elevated levels of D-dimers in critically ill COVID-19 patients) within the pulmonary vasculature also results in diminished perfusion of some well ventilated areas increasing the collective degree of $\mathrm{V} / \mathrm{Q}$ mismatch. ${ }^{14,16,33}$

The formation of hyaline membranes in combination with loss of hypoxic vasoconstriction, creates an environment where the hyperdynamic pulmonary circulation does not allow for enough time for red blood cells to equilibrate their oxygen uptake. This produces an impaired diffusion capacity which has been linked to the severity of the disease. ${ }^{33}$

The combination of these mechanisms can result in severe hypoxaemia despite the relative preservation of lung mechanics as opposed to scenarios where hypoxaemia is primarily driven by extensive loss of aerated tissue (shunt). Mild hypoxaemia (>60 $\mathrm{mmHg}$ ) produces little alteration of respiratory drive. As the hypoxaemia worsens, there is intensification of respiratory drive but the preservation of $\mathrm{Crs}$ means that increased tidal volumes can be achieved without a substantial increase in effort or feeling of discomfort (dyspnoea). ${ }^{33}$

\section{Use of lung protective ventilation}

Interestingly, compliance with lung protective ventilation was higher on average than that reported by the recent LUNGSAFE study, irrespective of the severity of the ARDS..$^{15}$ As reported by the LUNGSAFE investigators, one of the reasons for the lack of compliance with lung protective ventilatory strategies was the underdiagnosis of ARDS. ${ }^{35}$ In contrast, physicians the world over, undoubtedly enlightened by the explosion of information associated with all aspects of the COVID-19 pandemic, have readily anticipated the possibility of ARDS in patients with COVID-19 pneumonia thereby instituting the expected management protocols. Prone ventilation was commonly utilised with most studies noting good responses in terms of oxygenation and/or improved recruitability. $711,13,15,20$

\section{Conclusion}

ARDS is a heterogeneous syndrome rather than a specific disease, encompassing a wide variety of aetiologies, defined and severity 
stratified by the presence and degree of hypoxaemia. Despite some apparent characteristics to the contrary, CARDS is neither a separate pathophysiological nor clinical entity. It is remarkable that a disease caused by a singular microorganism can produce such a myriad of presentations. COVID-19 is forcing practitioners to reconsider the current treatment guidelines for ARDS, which depends on the $\mathrm{PaO}_{2}: \mathrm{FiO}_{2}$ ratio as a surrogate for intrapulmonary shunting in order to escalate therapies. ${ }^{8}$ Nevertheless, the use of current ARDS treatment protocols cannot be strongly argued against based on the existing evidence.

However, it is worth remembering that the current definition of ARDS requires the presence of a PEEP of at least $5 \mathrm{cmH}_{2} 0 .{ }^{36}$ This essentially limits the discussion of CARDS to only those COVID-19 patients who are receiving mechanical ventilation. The decision to initiate mechanical ventilation is a complex one and against the backdrop of a pandemic, there was always likely to be a steep learning curve. It is possible that a proportion of severely hypoxaemic patients may not have needed invasive mechanical ventilation based on the enhanced understanding of the number of potential pathophysiological mechanisms of hypoxaemia in COVID-19. The somewhat unexpected success of HFNC is perhaps testimony to that. ${ }^{5}$ It seems that now more than ever, a shift from syndromic management to a strategy employing personalised and precision medicine would make the need for a diagnosis of ARDS obsolete and render this debate moot.

\section{ORCID:}

\section{KD Naidoo (1) https://orcid.org/0000-0001-5745-4351}

\section{References}

1. Gattinoni L, Chiumello D, Caironi P, et al. CoVID-19 pneumonia: different respiratory treatments for different phenotypes? Intensive Care Med. 2020;46:1099-102. https://doi.org/10.1007/s00134-020-06033-2.

2. Gattinoni L, Chiumello D, Rossi S. COVID-19 pneumonia: ARDS or not? Crit Care. 2020;24:154. https://doi.org/10.1186/s13054-020-02880-z.

3. Marini JJ, Gattinoni L. Management of COVID-19 respiratory distress. JAMA. 2020;323:2329-30. https://doi.org/10.1001/jama.2020.6825.

4. Liu X, Liu X, Xu Y, et al. Ventilatory ratio in hypercapnic mechanically ventilated patients with COVID-19-associated acute respiratory distress syndrome. Am J Respir Crit Care Med. 2020;201:1297-9. https://doi.org/10.1164/ rccm.202002-0373LE.

5. Lalla U, Allwood BW, Louw EH, et al. The utility of high-flow nasal cannula oxygen therapy in the management of respiratory failure secondary to COVID-19 pneumonia. S Afr Med J. 2020;110:432.

6. Villarreal-Fernandez E, Patel R, Golamari R, et al. A plea for avoiding systematic intubation in severely hypoxemic patients with COVID-19-associated respiratory failure. Crit Care. 2020;24:337. https://doi.org/10.1186/s13054-020-03063-6.

7. Pan C, Chen L, Lu C, et al. Lung recruitability in COVID-19-associated acute respiratory distress syndrome: a single-center, observational study. Am J Respir Crit Care Med. 2020;201(10):1294-7. https://doi.org/10.1164/ rCcm.202003-0527LE.

8. Alessandri F, Pugliese F, Ranieri VM. The role of rescue therapies in the treatment of severe ARDS. Respir Care. 2018;63(1):92-101. https://doi.org/10.4187/ respcare.05752.

9. Copin $M$, Parmentier E, Duburcq T, et al. Time to consider histologic pattern of lung injury to treat critically ill patients with COVID-19 infection. Intensive Care Med. 2020;46:1124-6. https://doi.org/10.1007/s00134-020-06057-8.

10. Tobin $M$, Laghi $F$, Jubran A. Caution about early intubation and mechanical ventilation in COVID-19. Ann Intensive Care. 2020;10:78. https://doi.org/10.1186/ s13613-020-00692-6.

11. Ziehr DR, Alladina J, Petri CR, et al. Respiratory pathophysiology of mechanically ventilated patients with COVID-19: a cohort study. Am J Respir Crit Care. 2020;201(12):1560-4. https://doi.org/10.1164/rccm.202004-1163LE.
12. Gattinoni L, Coppola S, Cressoni M, et al. COVID-19 does not lead to a "typical" acute respiratory distress syndrome. Am J Respir Crit Care Med. 2020;201(10):1299-1300. https://doi.org/10.1164/rccm.202003-0817LE.

13. Schenck EJ, Hoffman $K$, Goyal $P$, et al. Respiratory mechanics and gas exchange in COVID-19-associated respiratory failure. Ann Am Thorac Soc. 2020;17(9):115861. https://doi.org/10.1513/AnnalsATS.202005-427RL.

14. Diehl J-L, Peron, N, Chocron R, et al. Respiratory mechanics and gas exchanges in the early course of COVID-19 ARDS: a hypothesis-generating study. Ann Intensive Care. 2020;10:95. https://doi.org/10.1186/s13613-020-00716-1.

15. Ferrando C, Suarez-Sipmann F, Mellado-Artigas R, et al. Clinical features, ventilatory management, and outcome of ARDS caused by COVID-19 are similar to other causes of ARDS. Intensive Care Med. 2020. https://doi.org/10.1007/ s00134-020-06192-2.

16. Grasselli G, Tonetti T, Protti A, et al. Pathophysiology of COVID-19-associated acute respiratory distress syndrome: a multicenter prospective observationa study. Lancet. 2020. https://doi.org/10.1016/S2213-2600(20)30370-2.

17. Grieco DL, Bongiovanni F, Chen L, et al. Respiratory physiology of COVID-19induced respiratory failure compared to ARDS of other etiologies. Crit Care. 2020;24:529. https://doi.org/10.1186/s13054-020-03253-2.

18. Mauri T, Spinelli E, Scotti E, et al. Potential for lung recruitment and ventilationperfusion mismatch in patients with the acute respiratory distress syndrome from coronavirus disease 2019*. Crit Care Med. 2020;48(8):1129-34. https://doi. org/10.1097/CCM.0000000000004386.

19. Beloncle FM, Pavlovsky B, Desprez C, et al. Recruitability and effect of PEEP in SARS-Cov-2-associated acute respiratory distress syndrome. Ann Intensive Care. 2020;10:55. https://doi.org/10.1186/s13613-020-00675-7.

20. Roesthuis L, Van den Berg M, Van der Hoeven $H$. Advanced respiratory monitoring in COVID-19 patients: use less PEEP! Crit Care. 2020;24:230. https:// doi.org/10.1186/s13054-020-02953-z.

21. Haudebourg A-F, Perier F, Tuffet $S$, et al. Respiratory mechanics of COVID-19 vs non-COVID-19 associated acute respiratory distress syndrome. Am J Respir Crit Care Med. 2020;202(2):287-90. https://doi.org/10.1164/rccm.202004-1226LE.

22. Sinha $\mathrm{P}$, Calfee CS, Beitler JR, et al. Physiologic analysis and clinical performance of the ventilatory ratio in acute respiratory distress syndrome. Am J Respir Crit Care Med. 2019;199(3):333-41. https://doi.org/10.1164/rccm.201804-06920C.

23. Bhatraju PK, Ghassemieh BJ, Nichols $M$, et al. Covid-19 in critically ill patients in the Seattle region-case series. N Engl J Med. 2020;382:2012-22. https://doi. org/10.1056/NEJMoa2004500.

24. Cummings MJ, Baldwin MR, Abrams D, et al. Epidemiology, clinical course and outcomes of critically ill adults with COVID-19 in New York City: a prospective cohort study. Lancet. 2020;395:1763-70. https://doi.org/10.1016/ S0140-6736(20)31189-2.

25. Bos LD, Paulus F, Vlaar APJ, et al. Subphenotyping acute respiratory distress syndrome in COVID-19 patients: consequences for ventilator management. Ann Am Thorac Soc. 2020;17(9):1161-3. https://doi.org/10.1513/ AnnalsATS.202004-376RL.

26. Laverdure F, Delaporte A, Bouteau A, et al. Impact of initial respiratory compliance in ventilated patients with acute respiratory distress syndrome related to COVID-19. Crit Care. 2020;24:412. https://doi.org/10.1186/ s13054-020-03133-9.

27. Naidoo KD, Kloeck DA, Mathivha LR. The calm before the storm. ICU Management and Practice. 2020;20(1):60-3.

28. Tobin MJ, Laghi F, Jubran A. Why COVID-19 silent hypoxemia is baffling to physicians. Am J Respir Crit Care Med. 2020;202(3):356-60. https://doi. org/10.1164/rccm.202006-2157CP.

29. Coppo A, Bellani G, Winterton D, et al. Feasibility and physiological effects of prone positioning in non-intubated patients with acute respiratory failure due to COVID-19 (PRON-COVID): a prospective cohort study. Lancet Respir Med. 2020;8(8):765-74. https://doi.org/10.1016/S2213-2600(20)30268-X.

30. Telias I, Katira BH, Brochard L. Is the prone position helpful during spontaneous breathing in patients with COVID-19? JAMA. 2020;323(22):2265-7. https://doi. org/10.1001/jama.2020.8539.

31. Bellani G, Laffey JG, Pham T, et al. Noninvasive ventilation of patients with acute respiratory distress syndrome. Insights from the LUNG SAFE study. Am J Respir Crit Care Med. 2017;195(1):67-77. https://doi.org/10.1164/rccm.201606-1306OC.

32. Piraino T. Noninvasive respiratory support in acute hypoxemic respiratory failure. Respir Care. 2019;64:638-46. https://doi.org/10.4187/respcare.06735.

33. Dhont S, Derom E, Van Braekel E, Depuydt P, Lambrecht BN. The pathophysiology of 'happy'hypoxemia in COVID-19. Respir Res. 2020;21:198. https://doi. org/10.1186/s12931-020-01462-5.

34. Ackermann $M$, Verleden $S E$, Kuehnel $M$, et al. Pulmonary vascular endothelialitis, thrombosis, and angiogenesis in Covid-19. N Engl J Med. 2020;383:120-28. https://doi.org/10.1056/NEJMoa2015432.

35. Bellani G, Pham T, Laffey JG. Missed or delayed diagnosis of ARDS: a common and serious problem. Intensive Care Med. 2020;46:1180-83. https://doi. org/10.1007/s00134-020-06035-0.

36. ARDS Definition Task Force. Acute respiratory distress syndrome: the Berlin definition. JAMA. 2012;307(23):2526-33. https://doi.org/10.1001/jama.2012.5669. 